\title{
NACHWEIS DER ORIGINALSEITEN UND ANGABEN ZUR REKONSTRUKTION
}

In der folgenden Tabelle werden die von den Hrsg. veröffentlichten Originalbl. jeweils einzeln unter Angabe der Seiten- und Zeilenzahl (sowie des Wortanfangs und-endes) ihrer Entsprechung in den drei Teilbänden der vorliegenden Edition nachgewiesen. Zusätzlich werden die für die Rekonstruktion des ursprünglichen Zusammenhangs der Mss. wichtigen Angaben, die sich auf den Originalbl. befinden (wie Paginierungen, Signaturen und Datierungen bzw. diesbezügliche Hinweise), wiedergegeben, und zwar nach folgendem Schema:

Spalte $a=$ Seiten- und Zeilenbereich in dem jeweiligen Teilband dieser Ausgabe

Spalte $b=$ Originalmanuskript mit Blattzahlen nach der offiziellen Zählung des Husserl-Archivs Leuven

Spalte $c=$ Originale Paginierung des Bl.

Spalte $d=$ Weitere Paginierungen

Spalte e $=$ Signaturangaben und Bemerkungen auf den Originalbl.

Spalte $f=$ Datierungshinweise

Alle kursivierten bzw. in spitzen Kl. stehenden Bemerkungen stammen von den Hrsg. 